\title{
Direct Numerical Simulations of Coupled Physicochemical and Thermal Processes Involved in Actinide-Fluid Interactions
}

\footnotetext{
MIN LIU ${ }^{1}$, QINJUN KANG ${ }^{2}$, HONGWU XU ${ }^{3}$

${ }^{1}$ Earth and Environmental Science Division, minl@lanl.gov ${ }^{2}$ Earth and Environmental Science Division, qkang@lanl.gov ${ }^{3}$ Earth and Environmental Science Division, hxu@lanl.gov

Detailed understanding of the interactions between actinide minerals and fluid is important for a range of applications including nuclear energy, environmental remediation, and global element cycling. We developed a grain-scale model coupling physicochemical and thermal processes to numerically investigate the actinide-fluid interactions in geological repository and reactor conditions. We performed direct numerical simulations of the $\mathrm{UO}_{2}$ corrosion with groundwater in a defective fuel rod with different breach orientations on cladding. The results show the corrosion rate is strongly dependent on the breach orientation. The highest corrosion rate of $\mathrm{UO}_{2}$ is calculated when the angle between the flow direction and the breach reaches 180 . The dependence of reaction rate and time on reactive surface area is explored. $\mathrm{UO}_{2}$ fuel with lower surface area demonstrates longer lifetime under corrosion conditions. The oxidation of $\mathrm{UO}_{2}$ with steam in defective fuel rod and its consequence to fuel behavior under reactor conditions is also investigated. The chemical reactions between $\mathrm{UO}_{2}$ and $\mathrm{H}_{2} \mathrm{O}$ steam are modelled by using the thermal-chemical model at grain scale. The effect of grain boundary and grain sizes on the temperature drops is considered for the fuel. The impact of oxidation on temperature drops and fuel effective thermal conductivity is studied. It is found oxidation can increase the temperature drops by lowering the fuel thermal conductivity. Oxidation effect on the fission gas diffusion in the fuel are also studied. In finer-grained fuel, the higher grain boundary density increases the transport rate of fission gas. This numerical method can provide a useful tool to quantitatively predict the reaction rate and help improve the fundamental understanding of the complex processes for $\mathrm{UO}_{2}$-fluid interactions. The numerical method developed may also be used for modelling metallic/non-metallic corrosion and the dissolution behavior of waste form phases containing other radionuclides and fission products with input parameters of specific elements/phases of interest.
} 